\title{
Pathophysiological aspects of insulin resistance in Atrial Fibrillation: novel therapeutic approaches
}

\author{
Saira Rafaqat ${ }^{*}$ (D) Sana Rafaqat ${ }^{1}$ and Simon Rafaqat $^{2}$
}

\begin{abstract}
Background: Insulin resistance is associated with metabolic disorders including diabetes, obesity, hypertension, and inflammation which are the risk factors for Atrial Fibrillation. Many studies have reported that type 2 diabetes and AF are related and also their prevalence is increasing globally. Moreover, insulin resistance begins the type 2 diabetes.

Main body: This review explains the pathophysiological aspects of insulin resistance in AF patients and discusses the drugs that are used to manage insulin resistance including Biguanides (metformin), thiazolidinediones (TZDs) [Pioglitazone, rosiglitazone], Sodium-glucose cotransporter 2 (SGLT2) inhibitors, Concentrated Insulin Products, Dipeptidyl peptidase-4 (DPP-4) Inhibitors, Glucagon-like peptide 1 (GLP-1) receptor Agonists, Pramlintide, Sulfonylureas, Meglitinides, a-Glucosidase Inhibitors, Colesevelam, Bromocriptine. This review will highlight a few major drugs that played a significant role in AF patients. For this purpose, many databases were used for reviewing the literature and keywords are used such as Insulin Resistance, Pathophysiology, Atrial Fibrillation, and Drugs.

Conclusion: This review article concludes that insulin resistance is related to AF. It also provides an outlook on the recent pathophysiological aspects of insulin resistance in AF; however, more studies are needed to clarify the management of insulin resistance in AF patients to prevent the development of type 2 diabetes.
\end{abstract}

Keywords: Insulin resistance, Pathophysiology, Atrial Fibrillation, Drugs

\section{Background}

Insulin resistance (IR) is defined as a pathological state in which cells fail to respond normally to the insulin hormone and also denotes impaired insulin sensitivity that facilitates glucose disposal $[1,2]$. IR is linked to numerous cardiovascular conditions because it is a common metabolic substrate. Moreover, insulin resistance is linked with diabetes, obesity and inflammation; all these are common risk factors of Atrial Fibrillation (AF) which is a cardiac arrhythmia that means irregular heartbeat or quivering of the atria instead of beating normally [3].

*Correspondence: saera.rafaqat@gmail.com

1 Lahore College for Women University, Near Wapda Flats Jail Rd, Jubilee Town, Lahore 54000, Punjab, Pakistan

Full list of author information is available at the end of the article
IR is commonly associated with obesity which is also a pathophysiologic factor of type 2 diabetes mellitus [4, 5]. The association between type 2 diabetes and insulin resistance had been reported in various studies because insulin resistance is an important and powerful predictor of future development of type 2 diabetes and also a therapeutic target once hyperglycemia is present [6].

IR is also a mutual denominator of metabolic syndrome, prediabetes, and diabetes. Those people who have developed type 2 diabetes usually pass through former phases of prediabetes and insulin resistance, these phases are often undiagnosed. Both insulin resistance and metabolic syndrome are the risk aspects for an incident of AF, but they have not been maintained by all clinical observations $[3,7-10]$. 
The overall 35 per cent risk of AF had been increased in type 2 diabetes patients as compared to age and sexmatched controls that included from the general population [11]. Various studies have reported the positive link between the risk of AF and diabetes. Likewise, two different meta-analyses, such as cohort and observational studies, had concluded that $30.0-40.0 \%$ risk of AF increased in individuals with type 2 diabetes, even after adjustment for, hyperthyroidism, hypertension, BMI, kidney disease, smoking, and coronary heart disease $[8,12]$. There are several risk factors of IR are also the risk factor for AF as explained in Fig. 1.

Google Scholar, PubMed, and Science direct were used to review the literature. 20 June 2021 was the last date of the search. Many keywords were used for searching the literature such as Insulin Resistance, Pathophysiology, Atrial Fibrillation and Drugs. According to the literature, much more data are available on insulin resistance, insulin resistance role in cardiovascular and AF. However, the current review article mainly focuses on the pathophysiological pathways/mechanisms of insulin resistance in $\mathrm{AF}$ and discusses the drugs that are used to manage IR, but this review will highlight their role in AF patients.

\section{Main text}

Basic introduction and Pathophysiology aspects of insulin resistance

Insulin is a peptide hormone that is secreted from the beta cells of the pancreatic islets of Langerhans and plays role in normal blood glucose levels by providing cellular glucose uptake, lipid and protein metabolism, regulating carbohydrate, facilitating growth, and cell division.
Clustering of abnormalities and related physical outcomes in insulin-resistant individuals are referred to as insulin resistance syndrome. Similarly, those individuals who are at high risk of cardiovascular diseases along with insulin resistance resulted in increased morbidity, which is referred to as metabolic syndrome [1,2].

IR is the impairment of glucose uptake in muscle and also the impairment of insulin action on lipid metabolism, for example in increment of lipolysis in adipocytes. It includes protein metabolism which involves the impairment of protein synthesis in muscle. In the same way, insulin resistance also affects the function of other organs of the body, for example, IR affects the vessels which are led to hypertension and vasoconstriction. Similarly, when insulin resistance affects the brain which resulted in a decrease in beta-cell mass and glucose sensing. As in the case of bone, it possibly decreases the strength and bone mass $[13,14]$.

Moreover, IR causes impaired glycogen synthesis and inhibits lipoprotein lipase activity in adipocytes as well as protein. Catabolism in skeletal muscles is the main cause of insulin resistance which is due to increased inflammatory cytokines, for example, leptin, tumour necrosis factor-alpha (TNF- $\alpha$ ), and interleukin-6 (IL-6) level that resulted in increased release of free fatty acids. Additionally, $30 \%$ of insulin-stimulated glucose disposal and IR both are stored in the liver which leads to impaired glucose output and fatty acid metabolism leading to increased triglycerides content and very low-density lipoprotein secretion $[15,16]$.

In the insulin resistance state, the mitogen-activated protein kinase pathway and phosphatidylinositol 3-kinase

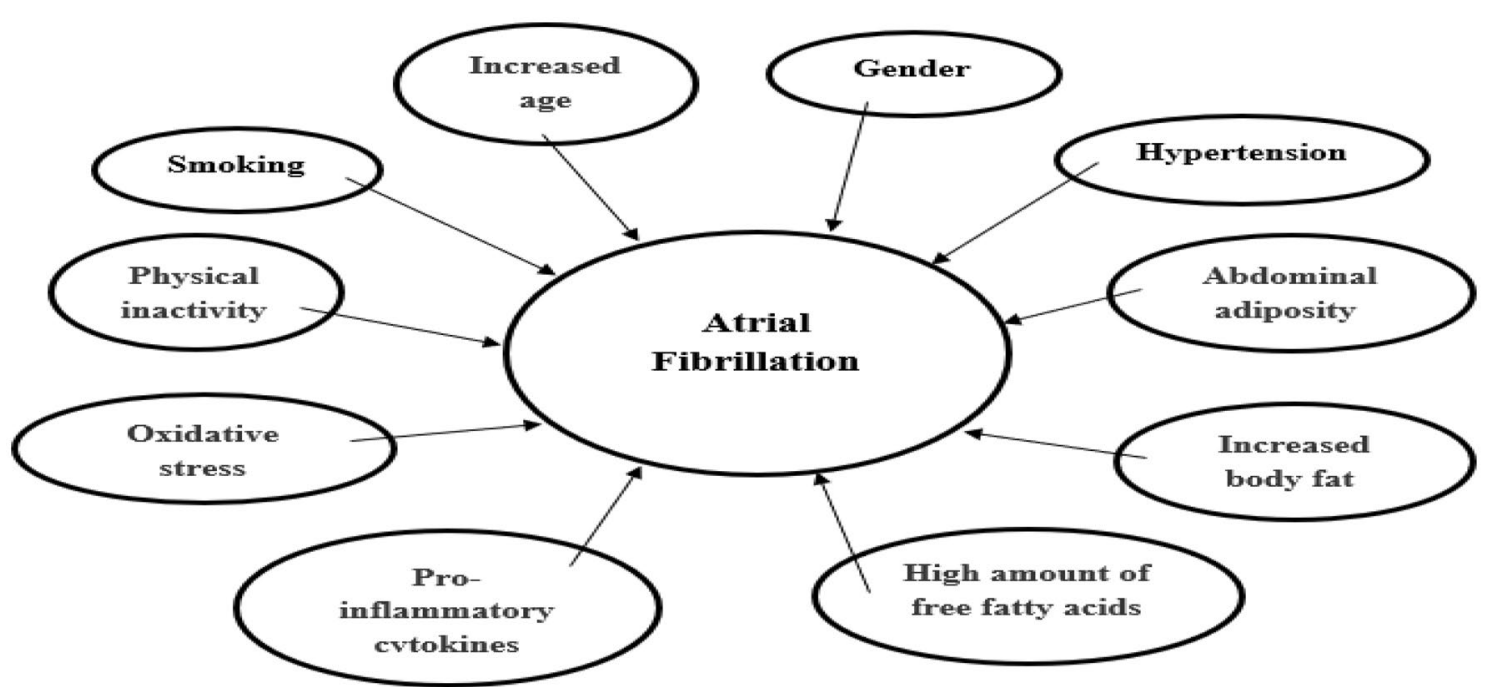

Fig. 1 Several risk factors of insulin resistance are also risk factors for the development and pathogenesis of AF. Source: Designed by the author with the help of review articles 
(PI3K) pathway are disturbed that caused the mitogenic effects of insulin in endothelial cells which lead to atherosclerosis $[16,17]$. Other studies have reported that insulin resistance is caused by abnormalities of the signaling pathways. Some other causes of insulin resistance are obesity, excess growth hormones, polycystic ovary disease, lipodystrophy (a genetic or acquired disease in which lipid is accumulated in the liver), excess glucocorticoids, autoantibodies to the insulin receptor, hemochromatosis, mutation in insulin receptor, and mutations of the peroxisomes proliferators activator receptor $y$ (PPARy) $[18,19]$.

\section{Pathophysiological aspects of IR in AF patients}

Various studies have been conducted to explain the relationship between insulin resistance and AF as explained in Table 1, and their pathophysiological relationship is also explained in the form of Fig. 2.

There are many risks factor for the predisposing of AF such as obesity, obstructive sleep apnea, aging, coronary artery disease, and hypertension [20]. Also, obesity increases the adipocytokines which promote low-grade chronic inflammation, upsetting insulin signaling and action which results in contributing to the development of diabetes mellitus and insulin resistance [21]. Left atrial remodeling is caused by adipocyte inflammation and oxidative stress which is associated with insulin resistance [22].

Another study also revealed that insulin resistance was linked to diabetes, inflammation, and obesity, all of these common risk factors for AF. Next, it is a common metabolic substrate that is linked to many cardiovascular diseases. Metabolic syndrome was also linked to insulin resistance which is also a risk factor and predisposition for AF. They found a validated research tool for the examination of insulin resistance such as the homeostasis model assessment index for insulin resistance leading to an incident of AF in the community. Further, metabolic syndrome and type 2 diabetes were associated with incident AF in which insulin resistance might be involved in the pathophysiological process of arrhythmia because insulin resistance might be a mediator between $\mathrm{AF}$ and Metabolic syndrome [3].

In the same way, Rutter study also demonstrated that insulin resistance plays an important role in the pathogenesis of left ventricular (LV) hypertrophy that makes associated with abnormal glucose tolerance and diabetes mellitus. The left atrial size increases as well as the insulin resistance increases in level. Insulin resistance causes hyperglycemia which is a condition in which the levels of glucose are higher which leads to increased cellular lipids, nonenzymatic glycation end products, insulinlike growth factors-mediated effects, altered myocardial protein degradation that results in LV remodeling, and left ventricular hypertrophy. Insulin resistance also causes hyperinsulinemia, a condition in which the levels of insulin is higher, which leads to potential mechanisms that altered matrix remodeling and vascular compliance, which increase renal sodium reabsorption and sympathetic activation resulting in LV remodeling and left ventricular hypertrophy [23].

Table 1 Studies showing Insulin Resistance (IR) role in Atrial Fibrillation (AF)

\begin{tabular}{|c|c|c|c|c|c|}
\hline Author & Place of study & Type of study & Year & Main findings & References \\
\hline Lee et al & Korea & A community-based, longitudinal study & 2020 & $\begin{array}{l}\text { A significant association between atrial fibrillation and } \\
\text { insulin resistance }\end{array}$ & {$[29]$} \\
\hline Polovina et al & Serbia & Editorial investigation & 2020 & Needs to promote further research & {$[83]$} \\
\hline Park et al & Korea & Prospective cohort study & 2019 & $\begin{array}{l}\text { IR (HOMA-IR) was connected with AF independently of } \\
\text { obesity in non-diabetics }\end{array}$ & {$[84]$} \\
\hline Chan et al & Taiwan & Experimental study on models & 2019 & $\begin{array}{l}\text { Insulin resistance contributes to increased AF suscep- } \\
\text { tibility }\end{array}$ & {$[32]$} \\
\hline Maria et al & United States & Experimental study on mice & 2018 & $\begin{array}{l}\text { During diabetes, insulin deficiency could have resulted } \\
\text { in alteration in energy production as well as glucose } \\
\text { transport in the atria which can increase the susceptibil- } \\
\text { ity to AF }\end{array}$ & {$[37]$} \\
\hline Fontes et al & Boston & Community-based cohort & 2012 & $\begin{array}{l}\text { They reported that there was no significant link } \\
\text { between incident AF and insulin resistance }\end{array}$ & {$[3]$} \\
\hline Shigematsu Y & Japan & Cross-sectional study & 2011 & $\begin{array}{l}\text { Insulin resistance may be a significant basic mechanism } \\
\text { for the beginning of AF in hypertrophic cardiomyopa- } \\
\text { thy }(\mathrm{HCM})\end{array}$ & {$[24]$} \\
\hline Östgren et al & Sweden & $\begin{array}{l}\text { Community-based, cross-sectional } \\
\text { observational study }\end{array}$ & 2004 & $\begin{array}{l}\text { The combined occurrence of Hypertension and type } \\
2 \text { diabetes are linked to AF in which insulin resistance } \\
\text { might be a common original mechanism }\end{array}$ & {$[31]$} \\
\hline
\end{tabular}




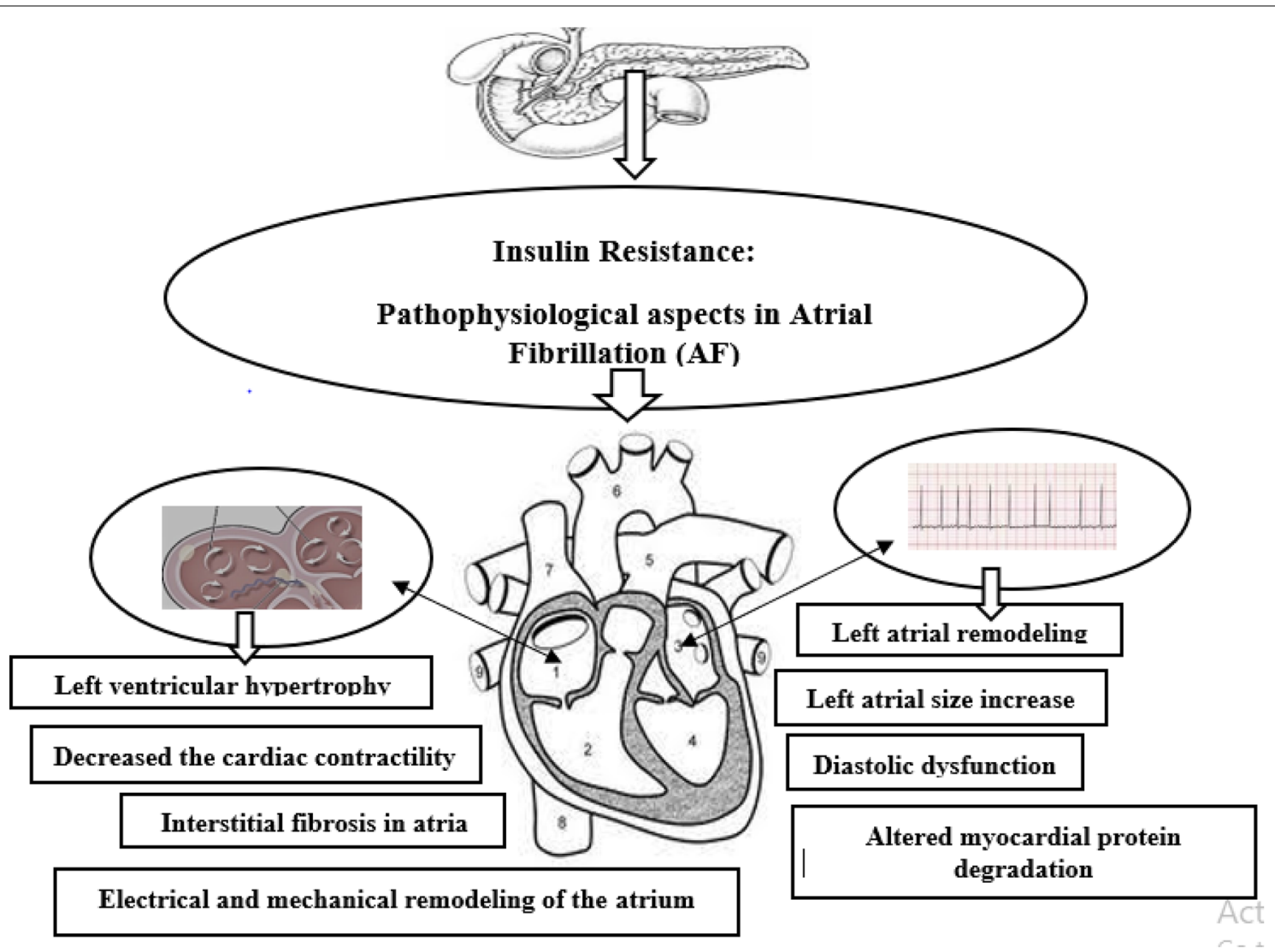

Fig. 2 Summary of pathophysiological aspects of insulin resistance in AF. Source: Designed by the author with the help of review articles

Insulin-like growth factor 1 (IGF-1) is a growth hormone that is a polypeptide that is synthesized by the liver. It was performed some similar functions due to its structural resemblance with insulin. It decreases cardiac contractility and plays important role in the pathogenesis of hypertrophic cardiomyopathy (HCM). Also, insulinlike growth factor-binding protein 3 (IGFBP-3) is a main binding protein. It has been involved in the synthesis of protein, diabetes, development of cells and bone metabolism, uncontrolled division of cells, and atherosclerosis. It reduced oxidative stress and also, IR was more common in non-diabetic patients with HCM and AF than in those with HCM and sinus rhythm. Moreover, it has been recommended that insulin resistance may be the underlying mechanism mediating the development of AF by the increase in Left Atrial size or impaired Left Ventricular diastolic function [24]. Moreover, Kannel et al. demonstrated that diabetes and insulin resistance are the risk factors for the development and progress of AF. Diabetes and glucose intolerance are risk factors for AF according to the Framingham Heart Study [25]. Also, hypertension and diabetes mellitus are predisposing to AF.
Left ventricular hypertrophy, diastolic dysfunction, and many other mechanisms are caused due to diabetes mellitus which further resulted in electrical and mechanical remodeling of the atrium [25-27].

Pastucha et al. used the validated research tools to define the relation of AF with IR. It is called the Homeostasis model assessment of insulin resistance. It was assessed by formula $=$ (Fasting plasma insulin [microunits per milliliter] $) \times$ (Fasting plasma glucose [micromole per litre])/22.5. Another formula was called Quantitative Insulin Sensitivity Check Index (QUICK) that was used for the early detection of insulin resistance in diagnostic values. It was assessed by the formula of QUICK $=1$ / [log fasting insulin $(\mathrm{uIU} / \mathrm{ml})+\log$ fasting blood glucose $(\mathrm{mg} / 100 \mathrm{ml})]$ [28]. In the same way, Lee et al. concluded that obesity, diabetes mellitus, and metabolic syndrome were found to be linked to an increase in the risk of AF in which insulin resistance was suspected to link these factors with the increase of the risk of AF. Moreover, the authors selected HOMA-IR to measure insulin resistance which is related to increasing the risk of Atrial Fibrillation. In the general population without diabetes, insulin 
resistance facilitates the unfavourable effects of obesity on the progress of Atrial Fibrillation [29].

In contrast, Garg et al. study concluded that there was no evidence of an association between the incidence of $\mathrm{AF}$ and either fasting or post-glucose load IR measures [30]. Also, Fontes et al. found no association between the incidence of $\mathrm{AF}$ and insulin resistance in which HOMA IR was $1.18,95 \%$ confidence interval 0.84 to $1.65, p=0.34$ [3]. Moreover, Östgren et al. study concluded the combined occurrence of hypertension and type 2 diabetes are linked to AF in which insulin resistance might be a common original mechanism and IR was measured by the homeostasis model assessment (HOMA) and resulted in the lost significance with adjustment for insulin resistance; $1.3(0.5-3.1)$ [31].

IR causes abnormal calcium homeostasis as well as interstitial fibrosis in atria which increased the ectopic activities and caused the change in the atria which play a role in AF genesis. IR also has a direct role in the expression of fibroblasts and transforming growth factor-beta 1 (TGF- $\beta 1$ ) in myocytes that results in atrial fibrosis. Ultimately, the authors suggested that upstream therapy targeting calcium/calmodulin-dependent protein kinase II (CaMKII), reducing oxidative stress, and transforming growth factor-beta 1 (TGF- $\beta 1$ ) are potentially effective strategies for preventing AF caused by a diet high in cholesterol, fat and sugar [32].

A large meta-analysis has reported that patients with diabetes have a 40 per cent greater risk for $\mathrm{AF}$ as compared to patients without diabetes [33]. Also, Yeh and Heijman studies have shown that IR was linked with numerous aspects of remodeling in the atria including hyperphosphorylated calcium handling-related proteins, increased oxidative stress, and increased interstitial fibrosis [34, 35].

Furthermore, Karam et al. conducted a study to explain that all these systemic diseases could share common and numerous Atrial Fibrillation-precipitating electrical and structural remodeling processes in atria that emphasize increased oxidative stress produced by nicotinamide adenine dinucleotide phosphate (NADPH) oxidase, dysfunctional mitochondrial and nitric oxide synthase [36]. Additionally, the disturbances in insulin and glucose might increase the arrhythmogenicity of the atrium which contains the pacemaker of the heart resulting in AF $[3,10,32]$. Similarly, Maria et al. explained that insulin and glucose disturbance was sufficient to induce AF susceptibility during mild diabetes [37].

\section{Pharmacological treatment options to control the insulin resistance in AF patients}

Diabetes mellitus (DM) is the most important risk factor for AF and also increases the incidence of AF which is also a predictor of stroke and thromboembolism. According to the literature, many drugs or medications are used for the treatment of type 2 diabetes in AF subjects. Whereas Church et al. [38] reported Pharmacological Treatment Options to treat the patients with severe insulin resistance, such as Biguanides (metformin), thiazolidinediones (TZDs) [Pioglitazone, rosiglitazone], Sodium-glucose cotransporter 2 (SGLT2) inhibitors, Concentrated Insulin Products, Dipeptidyl peptidase-4 (DPP-4) Inhibitors, Glucagon-like peptide 1 (GLP-1) receptor Agonists, Pramlintide, Sulfonylureas, Meglitinides, $\alpha$-Glucosidase Inhibitors, Colesevelam, Bromocriptine. However, this review article only focuses few major Pharmacological Treatment Options which are used to manage insulin resistance and their role in AF subjects. Table 2 explains the summary of the drugs that are used to manage insulin resistance and their role in AF patients.

\section{Metformin role in AF patients}

Metformin has many benefits in the case of cardiovascular protection such as left ventricular mass, myocardial infarction, cardiovascular death, reduction in blood pressure, heart failure, stroke, and all-cause mortality [39]. It also increases ketone body metabolism, promotes fatty acid oxidation, reduces lipid accumulation, induces the expression of glucose transporter in cardiomyocytes, all of which happened due to the activation of $5^{\prime}$ - adenosine monophosphate-activated protein kinase, and it also facilitated efficient energy use with reduction of metabolic stress $[40,41]$.

To decrease the incidence of $\mathrm{AF}$ in diabetic patients with and without myocardial infarction, metformin was associated to prevent the structural and electrical remodeling of the left atrium through improving calcium homeostasis, attenuating inflammation, activating $5^{\prime}$ adenosine monophosphate-activated protein kinase, increasing connexin-43 gap junction expression, attenuating intracellular reactive oxygen species, restoring small conductance calcium-activated potassium channels current [39]. Metformin is recommended for the treatment of type 2 diabetes mellitus and exerts an insulin-sensitizing effect [42] and might have anticancer, anti-inflammatory and antimicrobial and antiaging effects [43-46].

Ostropolets et al. found a reduced risk of atrial arrhythmias such as AF in patients on metformin monotherapy as compared to monotherapy with a thiazolidinedione or dipeptidyl peptidase 4 inhibitor medications [47]. Another recent study on the Taiwanese population found that both thiazolidinediones and metformin were linked with lowered risk of new-onset AF [48]. 


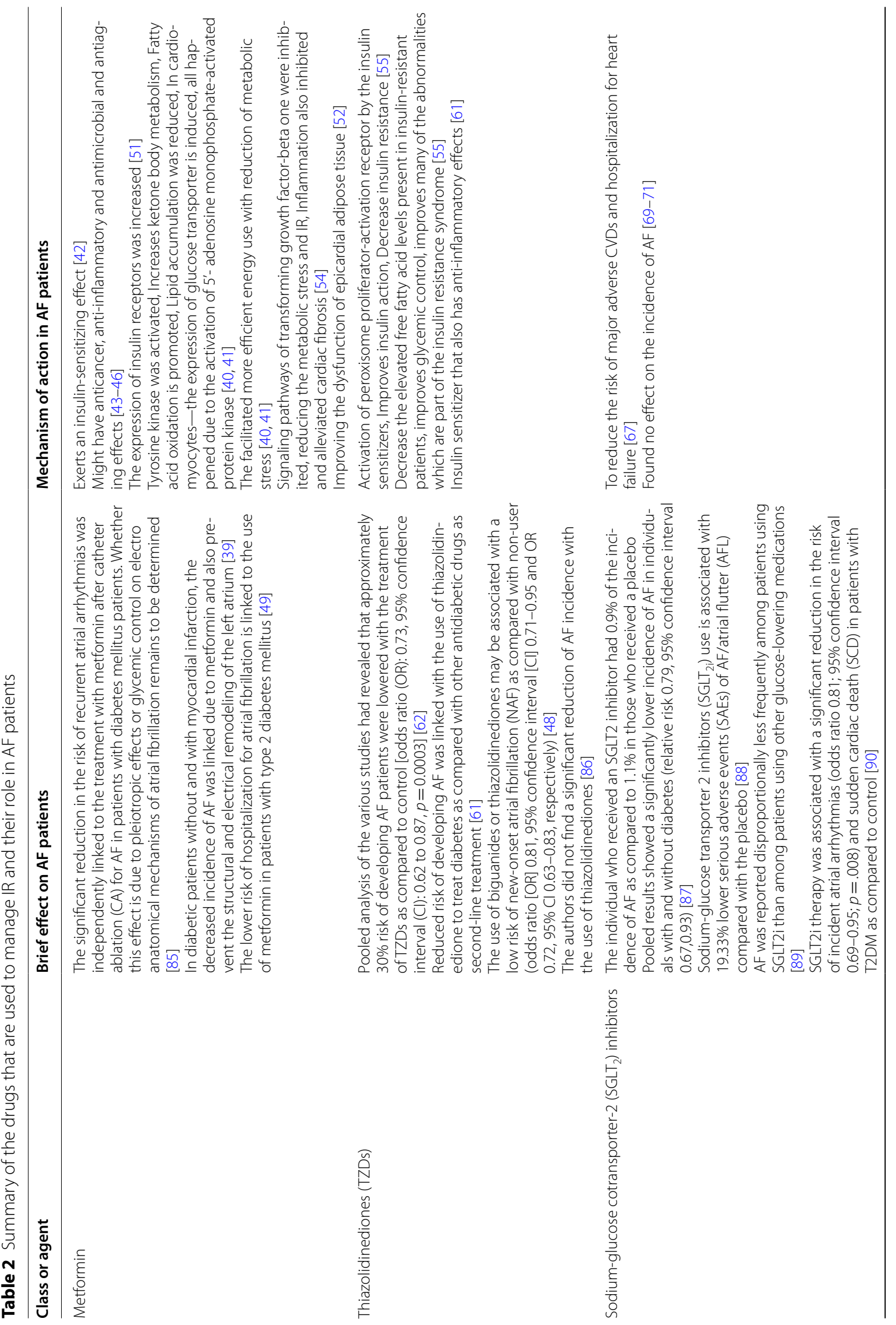




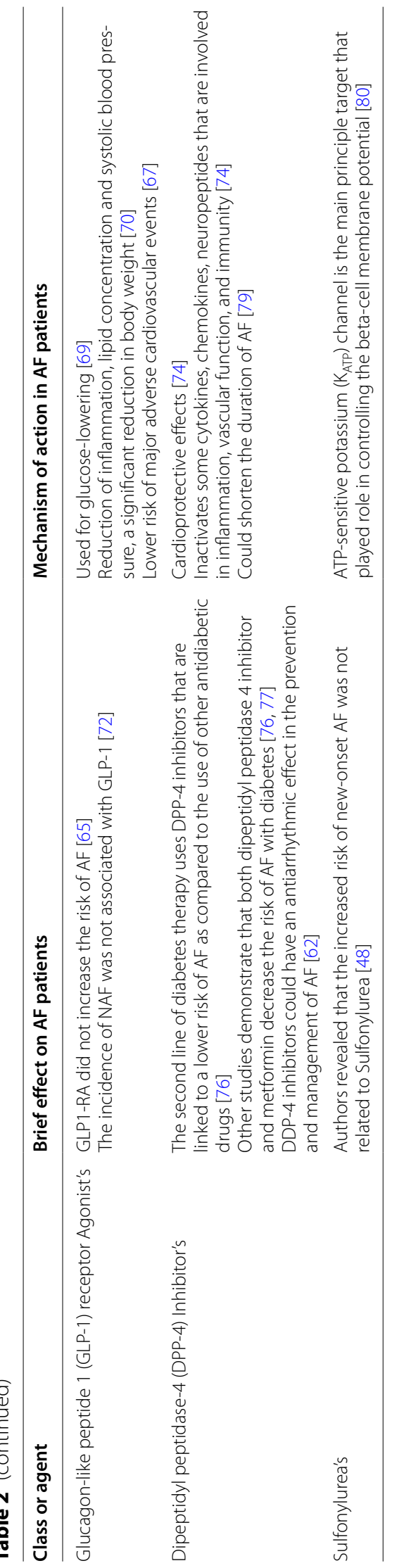


The lower risk of hospitalization for AF patients was linked to the use of metformin, with type 2 diabetes mellitus [49]. The estimated lifetime risk of AF is $22-26 \%$ while the 1.4-1.6-fold higher risk of diabetic patients [33, 50]. The $20 \%$ risk of AF was lower as a result of treatment with metformin. Insulin resistance was improved by metformin because the expression of insulin receptors was increased and tyrosine kinase was activated [51], whereas Packer et al. study has shown the reduction of AF by metformin, improving the dysfunction of epicardial adipose tissue [52]. The pro-fibrotic biomarkers (transforming growth factor-beta one, interleukin-6, tissue inhibitor of metalloproteinase-1, matrix metalloproteinase-1) play a role in causing AF $[41,53]$.

Interestingly, the signaling pathways of transforming growth factor-beta one was inhibited by metformin. The mechanism to reduce the AF linked to metformin use could be multifactorial and related to reducing the metabolic stress and insulin resistance, inflammation also inhibited and improvement of cardiac fibrosis [54]. Chan et al. explained that metformin might stop rapid pacinginducing atrial myocytes structural remodeling by reducing intracellular oxidation stress. Also, reported that this anti-diabetic medication with the improvement of insulin resistance could be effective in preventing atrial remodeling and AF in people with IR and prediabetes [32].

\section{Thiazolidinediones (TZDs) role in AF patients}

Thiazolidinediones (TZDs) are insulin sensitizers that act as peroxisome proliferator-activation receptor gamma (PPARgamma) agonists, which is developed to treat type 2 diabetic patients. Specifically, it improves insulin action and decreases insulin resistance. It also regulates molecules that affect insulin action and lipid metabolism. However, the exact mechanism is not clear that how these agents decrease insulin resistance but agents could decrease the elevated free fatty acid levels present in insulin-resistant patients and also change the body distribution of adipose tissue. Insulin-resistant type 2 diabetic patients treated with thiazolidinediones not only improve glycemic control but also decrease insulin resistance and also improve many of the abnormalities which are part of the insulin resistance syndrome [55]. Similarly, Saltiel et al. also explained that the action of thiazolidinediones to reduce insulin resistance by increasing insulin-dependent glucose disposal and also lowering hepatic glucose output. It is also designed to enhance the actions of insulin. It is represented a safe and effective new treatment in the clinical studies that include patients with type 2 diabetes, other syndromes characterized by insulin resistance [56].

Chao et al. research had reported the possible association between new-onset of AF and thiazolidinedione treatment in 12,605 patients with diabetes. During follow-up of 5 years, thiazolidinediones, after adjustment of age, baseline medications, as well as underlying diseases, were reduced the risk of AF occurrence by 31 per cent [57]. Moreover, $\mathrm{Gu}$ et al. revealed the improved preservation of sinus rhythm with pioglitazone and lowered the re-ablation rate in subjects with diabetes who underwent catheter ablation due to AF [58].

Numerous studies had reported that thiazolidinedione might be potentially beneficial for Atrial Fibrillation prevention because it is a class of peroxisome proliferator-activation receptor $-\gamma$ activator. Also, authors had reported that in DM patients, the thiazolidinedione could be a novel upstream therapy for $\mathrm{AF}$, but it required further large-scale randomized, controlled trials with long term follow-up period, which was used to evaluate the potential role of AF prevention [57, 59, 60].

Pallisgaard et al. study also reported that thiazolidinedione is an insulin sensitizer that also has anti-inflammatory effects. In conclusion, the author found the reduced risk of developing $\mathrm{AF}$ was linked with the use of thiazolidinedione to treat diabetes as compared with other antidiabetic drugs as second-line treatment [61]. Furthermore, Zhang et al. study reported, in a comprehensive meta-analysis on 130,854 diabetic patients, that protection against AF incidence may be due to the use of thiazolidinedione, also observed the beneficial effects of thiazolidinediones were consistently in both new-onset as well as recurrent AF. The reduced risk of incident AF was statistically associated with the use of Pioglitazone, whereas rosiglitazone use had not shown a statistically significant difference and protective effects of the use of thiazolidinedione [62]. Similarly, Simo et al. study also suggested the beneficial effect of the use of Pioglitazone on cardiovascular disease, while the increased risk of cardiovascular diseases was observed due to the use of rosiglitazone [63]. Lee et al. demonstrated in a metaanalysis on three randomized controlled trials, the use of pioglitazone could be associated with a 32 per cent lower risk of stroke recurrence in comparison with a placebo in 4980 subjects with previous stroke and either insulin resistance, prediabetes, or type 2 diabetes mellitus [64].

A recent meta-analysis had reported that cardiovascular and all-cause mortality, myocardial infarction, stroke and other major cardiovascular events had shown favourable effects by GPL-1 receptor agonists. In contrast, it is 
uncertain in the case of heart failure and data excluded about AF because of safety issues in this respect [65].

3. Sodium-glucose cotransporter-2 $\left(\mathrm{SGLT}_{2}\right)$ inhibitors role in $\mathrm{AF}$ patients

Sodium-glucose cotransporter 2 (SGLT2) inhibitors are used in the treatment of type 2 diabetes with metabolic syndrome with an elevated risk of cardiovascular diseases and also an insulin-independent class of oral antihyperglycemic medication [66]. Likewise, another drug sodium-glucose cotransporter-2 $\left(\mathrm{SGLT}_{2}\right)$ inhibitors used to reduce the risk of major adverse CVDs and hospitalization for heart failure [67]. In a meta-analysis of numerous clinical trials, NAF was not linked with $\mathrm{SGLT}_{2}$ inhibitors as compared to placebo [68]. Likewise, other studies including Dapagliflozin Effect on Cardiovascular Events (DECLARE), CANagliflozin Cardiovascular Assessment Study (CANVAS), BI 10773 [Empagliflozin] Cardiovascular Outcome Event Trial in Type 2 Diabetes Mellitus Patients (EMPAREG) outcomes, reported that there was no significant difference between $\mathrm{SGLT}_{2}$ inhibitors and new-onset atrial fibrillation (NAF). These studies suggest that $\mathrm{SGLT}_{2}$ inhibitors could prevent adverse cardiovascular events, on the incidence of $\mathrm{AF}$, and found no effect [69-71].

4. Glucagon-like peptide 1 (GLP-1) receptor Agonist's role in AF patients

In type 2 diabetes with low risk for hypoglycemia, a novel drug called Glucagon-like peptide-1 receptor agonists (GLP-1 RAs), was used for glucose-lowering [69]. It also played role in the reduction of inflammation, lipid concentration and systolic blood pressure and also a caused significant reduction in body weight. Therefore glucagon-like peptide-1 receptor agonists are suggested as candidates for use in diabetic patients with a high risk of cardiovascular diseases [70]. Similar, Newman et al. also stated another new class of diabetes medication including Glucagon-like peptide-1 receptor agonists linked to a lower risk of major adverse cardiovascular events [67]. Conversely, Monami et al. explained in a recent metaanalysis of data from several clinical trials, the incidence of NAF and Glucagon-like peptide-1 receptor agonists were not associated [72]. Korantzopoulos study also reported the better recovery to sinus rhythm with rosiglitazone in those isolated cases of patients with paroxysmal AF and diabetes. In Taiwan, a case-control study in 2018 showed a lower risk of developing AF was associated with the use of type 2 diabetes drugs $[48,73]$.

\section{Dipeptidyl peptidase-4 (DPP-4) Inhibitor's role in AF patients}

The new class of diabetes medication is dipeptidyl peptidase-4 inhibitors, which have cardioprotective effects. It also inactivates some cytokines, chemokines, neuropeptides that are involved in inflammation, vascular function, and immunity [74]. Ghorpade et al. also reported that silencing the expression of dipeptidyl peptidase- 4 inhibitors on hepatocytes suppressed inflammation of visceral adipose tissue (VAT) and insulin resistance, but this effect did not occur with sitagliptin, an orally administered dipeptidyl peptidase-4 inhibitor [75]. Moreover, in a recent cohort study, the second line diabetes therapy uses DPP-4 inhibitors that are linked to a lower risk of AF as compared to the use of other antidiabetic drugs [76].

Other studies demonstrate that both dipeptidyl peptidase 4 inhibitor and metformin decrease the risk of AF with diabetes [76, 77]. Moreover, another study had reported that dipeptidyl peptidase- 4 inhibitor prevents myocardial fibrosis, weight loss, improves myocardial hypertrophy, and active oxygen stress in obese mice with diabetes. Also, dipeptidyl peptidase- 4 inhibitor and vildagliptin might prevent atrial inflammation and lower the Atrial Fibrillation inducibility in spontaneously hypertensive rats' complications with diabetes mellitus [78]. In the same way, Yamamoto et al. reported that DDP-4 inhibitor alogliptin could shorten the duration of AF induced by ventricular tachy-pacing in rabbits with fibrotic atria [79]. Furthermore, DDP-4 inhibitors could have an antiarrhythmic effect in the prevention and management of AF [62].

\section{Sulfonylurea's role in AF patients}

The insulin secretion is stimulated from pancreatic beta-cells with the help of sulfonylureas and which is also being used to treat type 2 diabetes patients. ATPsensitive potassium $\left(\mathrm{K}_{\mathrm{ATP}}\right)$ channel is the main principle target that played role in controlling the beta-cell membrane potential. Glucose inhibits the $\mathrm{K}_{\mathrm{ATP}}$ channels or depolarization of the beta-cell membrane are caused by sulfonylureas, in turn, the opening of voltage-gated calcium channels are triggered, eliciting calcium influx and intracellular calcium are raised that stimulate the exocytosis of insulin-containing secreting granules. Moreover, a variety of other cell types, including skeleton muscle, some brain neurons, smooth and cardiac, have a high density of $\mathrm{K}_{\text {ATP }}$ channels which are opened by the response of metabolic stress that leads to inhibition of electrical activity and also involved in cerebral ischemic 
and cardiac, neuronal regulation of glucose homeostasis, control of vascular smooth muscle tone, and seizure protection [80].

Sulfonylurea therapy is linked with a 4.5 -fold increase in the risk of severe hypoglycemia as compared to metformin [81], whereas acute hypoglycemia had been linked with proarrhythmic because of sympathetic activation and could explain the overall link between NAF and sulfonylurea use [82]. To control the risk of AF development, numerous researchers had analyzed Sulfonylurea therapy as compared to other anti-diabetic medications. However, with studies exceptions, Liou et al. had revealed that increased risk of new-onset AF was not related to Sulfonylurea [48].

\section{Conclusion}

This review concludes that IR is associated with the development of AF which is also a risk factor for causing many pathophysiological aspects in AF, such as left atrial remodeling, left ventricular hypertrophy, left atrial size increased, interstitial fibrosis in atria, electrical and mechanical remodeling of the atrium, decreased cardiac contractility, and diastolic dysfunction. However, future studies are also required to control insulin resistance in AF patients that will not increase the prevalence of type 2 diabetes mellitus in AF patients.

\section{Abbreviations}

AF: Atrial Fibrillation; IR: Insulin resistance; TNF-a: Tumor necrosis factor-alpha; IL-6: Interleukin-6; PPARy: Peroxisome's proliferators activator receptor y; CVD: Cardiovascular disease; LDL: Low-density lipoprotein; HDL: High-density lipoprotein; HOMA: Homeostasis model assessment of insulin resistance; QUICK: Quantitative Insulin Sensitivity Check Index; LV: Left ventricular; HCM: Hypertrophic cardiomyopathy; IGF-1: Insulin-like growth factor 1; TGF- $\beta 1$ : Transforming growth factor-beta 1; CaMKII: Calcium/calmodulin-dependent protein kinase II; MAPK: Mitogenactivated protein kinases; NADPH: Nicotinamide adenine dinucleotide phosphate; GLP-1 Ras: Glucagon-like peptide-1 receptor agonists; SGLT $_{2}$ : Sodium-glucose cotransporter-2 inhibitors; TZDs: Thiazolidinediones; GLP-1 RAs: Glucagon-like peptide-1 receptor agonists; VAT: Visceral adipose tissue.
\end{abstract}

\section{Acknowledgements}

None.

\section{Authors' contributions}

SRM carried out the study design and data collection. SR wrote the manuscript. All authors read and approved the final manuscript. SR gave the editing services of the manuscript. All authors read and approved the final manuscript.

\section{Funding}

No funding was received. It was self-funded.

Availability of data and materials

Not applicable.

\section{Declarations}

Ethics approval and consent to participate Not applicable.

\section{Consent for publication}

Not applicable.

\section{Competing interests}

The authors declare that they have no competing interests.

\section{Author details}

${ }^{1}$ Lahore College for Women University, Near Wapda Flats Jail Rd, Jubilee Town, Lahore 54000, Punjab, Pakistan. ${ }^{2}$ Forman Christian College (A Chartered University), Zahoor Elahi Rd, Gulberg III, Lahore, Punjab 54600, Pakistan.

Received: 3 August 2021 Accepted: 9 November 2021

Published online: 08 March 2022

\section{References}

1. Cefalu WT. Insulin resistance: cellular and clinical concepts. Exp Biol Med. 2001;226(1):13-26.

2. Reaven $\mathrm{G}$. The metabolic syndrome or the insulin resistance syndrome? Different names, different concepts, and different goals. Endocrinol Metab Clin. 2004;33(2):283-303.

3. Fontes JD, Lyass A, Massaro JM, Rienstra M, Dallmeier D, Schnabel RB, Wang TJ, Vasan RS, Lubitz SA, Magnani JW, Levy D. Insulin resistance and atrial fibrillation (from the Framingham Heart Study). Am J Cardiol. 2012;109(1):87-90.

4. Ginsberg HN. Insulin resistance and cardiovascular disease. J Clin Investig. 2000;106(4):453-8.

5. Wild S, Roglic G, Green A, Sicree R, King H. Global prevalence of diabetes: estimates for the year 2000 and projections for 2030. Diabetes Care. 2004:27(5):1047-53

6. Taylor R. Insulin resistance and type 2 diabetes. Diabetes. 2012;61(4):778-9.

7. Choe WS, Choi EK, Han KD, Lee EJ, Lee SR, Cha MJ, Oh S. Association of metabolic syndrome and chronic kidney disease with atrial fibrillation: a nationwide population-based study in Korea. Diabetes Res Clin Pract. 2019;148:14-22.

8. Huxley RR, Filion KB, Konety S, Alonso A. Meta-analysis of cohort and case-control studies of type 2 diabetes mellitus and risk of atrial fibrillation. Am J Cardiol. 2011;108(1):56-62.

9. Cho ME, Craven TE, Cheung AK, Glasser SP, Rahman M, Soliman EZ, Stafford RS, Johnson KC, Bates JT, Burgner A, et al. The association between insulin resistance and atrial fibrillation: a cross-sectional analysis from SPRINT (Systolic Blood Pressure Intervention Trial). J Clin Hypertens (Greenwich). 2017;19(11):1152-61.

10. Hajhosseiny R, Matthews GK, Lip GY. Metabolic syndrome, atrial fibrillation, and stroke: tackling an emerging epidemic. Heart Rhythm. 2015;12(11):2332-43.

11. Ahmadi SS, Svensson AM, Pivodic A, Rosengren A, Lind M. Risk of atrial fibrillation in persons with type 2 diabetes and the excess risk in relation to glycaemic control and renal function: a Swedish cohort study. Cardiovasc Diabetol. 2020;19(1):1-2.

12. Aune D, Feng T, Schlesinger S, Janszky I, Norat T, Riboli E. Diabetes mellitus, blood glucose and the risk of atrial fibrillation: a systematic review and meta-analysis of cohort studies. J Diabetes Complicat. 2018;32(5):501-11.

13. Kawai M, de Paula FJ, Rosen CJ. New insights into osteoporosis: the bonefat connection. J Intern Med. 2012;272(4):317-29.

14. Jo J, Gavrilova O, Pack S, Jou W, Mullen S, Sumner AE, Cushman SW, Periwal V. Hypertrophy and/or hyperplasia: dynamics of adipose tissue growth. PLoS Comput Biol. 2009;5(3):e1000324.

15. Reaven GM. Pathophysiology of insulin resistance in human disease. Physiol Rev. 1995;75(3):473-86.

16. Wilcox G. Insulin and insulin resistance. Clin Biochem Rev. 2005;26(2):19-39.

17. Wu G, Meininger CJ. Nitric oxide and vascular insulin resistance. BioFactors. 2009;35(1):21-7.

18. Wang CC, Gurevich I, Draznin B. Insulin affects vascular smooth muscle cell phenotype and migration via distinct signaling pathways. Diabetes. 2003;52(10):2562-9. 
19. Gurnell M, Savage DB, Chatterjee VK, O'Rahilly S. The metabolic syndrome: peroxisome proliferator-activated receptor $\gamma$ and its therapeutic modulation. J Clin Endocrinol Metab. 2003;88(6):2412-21.

20. Magnani JW, Rienstra M, Lin H, et al. Atrial fibrillation: Current knowledge and future directions in epidemiology and genomics. Circulation. 2011;124:1982-93.

21. Vyas V, Lambiase P. Obesity and atrial fibrillation: Epidemiology, pathophysiology and novel therapeutic opportunities. Arrhythm Electrophysio Rev. 2019:8:28.

22. Rehman K, Akash MS. Mechanisms of inflammatory responses and development of insulin resistance: how are they interlinked? J Biomed Sci. 2016;23:87.

23. Rutter MK, Parise H, Benjamin EJ, Levy D, Larson MG, Meigs JB, Nesto RW, Wilson PW, Vasan RS. Impact of glucose intolerance and insulin resistance on cardiac structure and function: sex-related differences in the Framingham Heart Study. Circulation. 2003;107(3):448-54.

24. Shigematsu Y, Hamada M, Nagai T, Nishimura K, Inoue K, Suzuki J, Ogimoto A, Higaki J. Risk for atrial fibrillation in patients with hypertrophic cardiomyopathy: association with insulin resistance. J Cardiol. 2011;58(1):18-25.

25. Kannel WB, Abbott RD, Savage DD, McNamara PM. Epidemiologic features of chronic atrial fibrillation: the Framingham study. N Engl J Med. 1982;306(17):1018-22.

26. Velagaleti RS, Gona P, Chuang ML, Salton CJ, Fox CS, Blease SJ, Yeon SB, Manning WJ, O'Donnell CJ. Relations of insulin resistance and glycemic abnormalities to cardiovascular magnetic resonance measures of cardiac structure and function: the Framingham Heart Study. Circ Cardiovasc Imaging. 2010;3(3):257-63.

27. Watanabe M, Yokoshiki H, Mitsuyama H, Mizukami K, Ono T, Tsutsui $\mathrm{H}$. Conduction and refractory disorders in the diabetic atrium. Am J Physiol Heart Circ Physiol. 2012;303(1):H86-95.

28. Pastucha D, Filipcikova R, Horáková D, Radová L, Marinov Z, Malincikova J, Kocvrlich M, Horák S, Bezdickova M, Dobias M. The incidence of metabolic syndrome in obese Czech children: the importance of early detection of insulin resistance using homeostatic indexes HOMA-IR and QUICKI. Physiol Res. 2013;62(3):277.

29. Lee Y, Cha SJ, Park JH, Shin JH, Lim YH, Park HC, Shin J, Kim CK, Park JK. Association between insulin resistance and risk of atrial fibrillation in nondiabetics. Eur J Prev Cardiol. 2020;27(18):1934-41.

30. Garg PK, Biggs ML, Kaplan R, Kizer JR, Heckbert SR, Mukamal KJ. Fasting and post-glucose load measures of insulin resistance and risk of incident atrial fibrillation: the Cardiovascular Health Study. Nutr Metab Cardiovasc Dis. 2018;28(7):716-21.

31. Östgren CJ, Merlo J, Råstam L, Lindblad U, Skaraborg Hypertension and Diabetes Project. Atrial fibrillation and its association with type 2 diabetes and hypertension in a Swedish community. Diabetes Obes Metab. 2004:6(5):367-74.

32. Chan YH, Chang GJ, Lai YJ, Chen WJ, Chang SH, Hung LM, Kuo CT, Yeh YH. Atrial fibrillation and its arrhythmogenesis associated with insulin resistance. Cardiovasc Diabetol. 2019;18(1):1-4.

33. Bell DSH, Goncalves E. Atrial fibrillation and type 2 diabetes: prevalence, etiology, pathophysiology and effect of anti-diabetic therapies. Diabetes.

34. Yeh YH, Wakili R, Qi XY, Chartier D, Boknik P, Kaab S, Ravens U, Coutu P, Dobrev D, Nattel S. Calcium-handling abnormalities underlying atrial arrhythmogenesis and contractile dysfunction in dogs with congestive heart failure. Circ Arrhythm Electrophysiol. 2008;1(2):93-102.

35. Heijman J, Guichard JB, Dobrev D, Nattel S. Translational challenges in atrial fibrillation. Circ Res. 2018;122(5):752-73.

36. Karam BS, Chavez-Moreno A, Koh W, Akar JG, Akar FG. Oxidative stress and inflammation as central mediators of atrial fibrillation in obesity and diabetes. Cardiovasc Diabetol. 2017;16(1):120.

37. Maria Z, Campolo AR, Scherlag BJ, Ritchey JW, Lacombe VA. Dysregulation of insulin-sensitive glucose transporters during insulin resistanceinduced atrial fibrillation. BBA Mol Basis Dis. 2018;1864(4):987-96.

38. Church TJ, Haines ST. Treatment approach to patients with severe insulin resistance. Clinical Diabetes. 2016;34(2):97-104

39. Nantsupawat T, Wongcharoen W, Chattipakorn SC, Chattipakorn N. Effects of metformin on atrial and ventricular arrhythmias: evidence from cell to patient. Cardiovasc Diabetol. 2020;19(1):1-4.
40. Bai F, Liu Y, Tu T, Li B, Xiao Y, Ma Y, et al. Metformin regulates lipid metabolism in a canine model of atrial fibrillation through AMPK/PPAR-a/VLCAD pathway. Lipids Health Dis. 2019;18:109.

41. Harada M, Melka J, Sobue Y, Nattel S. Metabolic considerations in atrial fibrillation-mechanistic insights and therapeutic opportunities. Circ J. 2017:81:1749-57.

42. Yang $X, X u Z$ Z, Zhang $C$, Cai Z, Zhang J. Metformin, beyond an insulin sensitizer, targeting heart and pancreatic $\beta$ cells. Biochim Biophys Acta. 2017;1863:1984-90

43. Maniar K, Moideen A, Mittal A, Patil A, Chakrabarti A, Banerjee D. A story of metformin-butyrate synergism to control various pathological conditions as a consequence of gut microbiome modification: genesis of a wonder drug? Pharmacol Res. 2017;117:103-28.

44. Tseng $\mathrm{CH}$. Metformin and Helicobacter pylori infection in type 2 diabetes patients. Diabetes Care. 2018;41:e42-3.

45. Tseng $\mathrm{CH}$. Metformin decreases risk of tuberculosis infection in type 2 diabetes patients. J Clin Med. 2018;7:264.

46. Tseng $\mathrm{CH}$. Metformin and risk of chronic obstructive pulmonary disease in diabetes patients. Diabetes Metab. 2019;45:184-90.

47. Ostropolets A, Elias PA, Reyes MV, Wan EY, Pajvani UB, Hripcsak G, Morrow JP. Metformin is associated with a lower risk of atrial fibrillation and ventricular arrhythmias compared with sulfonylureas: an observational study. Circ Arrhythm Electrophysiol. 2021;14(3): e009115.

48. Liou YS, Yang FY, Chen HY, Jong GP. Antihyperglycemic drugs use and new-onset atrial fibrillation: a population-based nested case control study. PLOS ONE. 2018;13(8):e0197245.

49. Tseng $\mathrm{CH}$. Metformin use is associated with a lower incidence of hospitalization for atrial fibrillation in patients with type 2 diabetes mellitus. Front Med. 2020;7:1031.

50. Andrade J, Khairy P, Dobrev D, Nattel S. The clinical profile and pathophysiology of atrial fibrillation: relationships among clinical features, epidemiology, and mechanisms. Circ Res. 2014;114:1453-68.

51. Viollet B, Guigas B, Sanz Garcia N, Leclerc J, Foretz M, Andreelli F. Cellular and molecular mechanisms of metformin: an overview. Clin Sci. 2012;122:253-70.

52. Packer M. Drugs that ameliorate epicardial adipose tissue inflammation may have discordant effects in heart failure with a preserved ejection fraction as compared with a reduced ejection fraction. J Card Fail. 2019;25:986-1003.

53. Stanciu AE, Vatasescu RG, Stanciu MM, Serdarevic N, Dorobantu M. The role of pro-fibrotic biomarkers in paroxysmal and persistent atrial fibrillation. Cytokine. 2018;103:63-8.

54. Song Y, Chen Y, Li Y, Lyu X, Cui J, Cheng Y, et al. Metformin inhibits TGF- $\beta 1$-induced epithelial-to-mesenchymal transition-like process and stem-like properties in GBM via AKT/mTOR/ZEB1 pathway. Oncotarget. 2017:9:7023-35.

55. Lebovitz HE, Banerji MA. Insulin resistance and its treatment by thiazolidinediones. Recent Prog Horm Res. 2001;56:265-94.

56. Saltiel AR, Olefsky JM. Thiazolidinediones in the treatment of insulin resistance and type II diabetes. Diabetes. 1996;45(12):1661-9.

57. Chao TF, Leu HB, Huang CC, Chen JW, Chan WL, Lin SJ, Chen SA. Thiazolidinediones can prevent new onset atrial fibrillation in patients with noninsulin dependent diabetes. Int J Cardiol. 2012;156(2):199-202.

58. Gu J, Liu X, Wang X, et al. Beneficial effect of pioglitazone on the outcome of catheter ablation in patients with paroxysmal atrial fibrillation and type 2 diabetes mellitus. Europace. 2011;13:1256-61.

59. Liu T, Li G. Thiazolidinediones as novel upstream therapy for atrial fibrillation in diabetic patients: a review of current evidence. Int J Cardiol. 2012;156(2):215-6.

60. Anglade MW, Kluger J, Michael White C, Aberle J, Coleman CI. Thiazolidinedione use and post-operative atrial fibrillation: a US nested case-control study. Curr Med Res Opin. 2007;23(11):2849-55.

61. Pallisgaard JL, Lindhardt TB, Staerk L, Olesen JB, Torp-Pedersen C, Hansen $\mathrm{ML}$, Gislason $\mathrm{GH}$. Thiazolidinediones are associated with a decreased risk of atrial fibrillation compared with other antidiabetic treatment: a nationwide cohort study. Eur Heart J Cardiovasc Pharmacother. 2017;3(3):140-6.

62. Zhang Z, Zhang X, Korantzopoulos P, Letsas KP, Tse G, Gong M, Meng L, Li G, Liu T. Thiazolidinedione use and atrial fibrillation in diabetic patients: a meta-analysis. BMC Cardiovasc Disord. 2017;17(1):1-9. 
63. Simo R, Rodriguez A, Caveda E. Different effects of thiazolidinediones on cardiovascular risk in patients with type 2 diabetes mellitus: pioglitazone vs rosiglitazone. Curr Drug Saf. 2010;5(3):234-44.

64. Lee M, Saver JL, Liao HW, Lin CH, Ovbiagele B. Pioglitazone for secondary stroke prevention: a systematic review and meta-analysis. Stroke. 2017;48(2):388-93.

65. Nreu B, Dicembrini I, Tinti F, Sesti G, Mannucci E, Monami M. Major cardiovascular events, heart failure, and atrial fibrillation in patients treated with glucagon-like peptide-1 receptor agonists: an updated meta-analysis of randomized controlled trials. Nutr Metab Cardiovasc Dis. 2020;30(7):1106-14.

66. Olgar Y, Turan B. A sodium-glucose cotransporter 2 (SGLT2) inhibitor dapagliflozin comparison with insulin shows important effects on Zn2+-transporters in cardiomyocytes from insulin-resistant metabolic syndrome rats through inhibition of oxidative stress. Can J Physiol Pharmacol. 2019;97(6):528-35.

67. Newman JD, Vani AK, Aleman JO, Weintraub HS, Berger JS, Schwartzbard AZ. The changing landscape of diabetes therapy for cardiovascular risk reduction: JACC State-of-the-Art Review. J Am Coll Cardiol. 2018;72:1856-69.

68. Usman MS, Siddiqi TJ, Memon MM, et al. Sodium-glucose co-transporter 2 inhibitors and cardiovascular outcomes: a systematic review and metaanalysis. Eur J Prev Cardiol. 2018;25:495-502.

69. Wiviott SD, Raz I, Bonaca MP, et al. Dapagliflozin and cardiovascular outcomes in type 2 diabetes. N Engl J Med. 2019;380:347-57.

70. Zinman B, Wanner C, Lachin JM, et al. Empagliflozin, cardiovascular outcomes, and mortality in type 2 diabetes. N Engl J Med. 2015;373:2117-28.

71. Neal B, Perkovic V, Mahaffey KW, et al. Canagliflozin and cardiovascular and renal events in type 2 diabetes. N Engl J Med. 2017;377:644-57.

72. Monami M, Nreu B, Scatena A, et al. Glucagon-like peptide-1 receptor agonists and atrial fibrillation: a systematic review and meta-analysis of randomized controlled trials. J Endocrinol Invest. 2017:40:1251-8.

73. Korantzopoulos P, Kokkoris S, Kountouris E, Protopsaltis I, Siogas K, Melidonis A. Regression of paroxysmal atrial fibrillation associated with thiazolidinedione therapy. Int J Cardiol. 2008;125:e51-3.

74. Fadini GP, Avogaro A. Cardiovascular effects of DPP-4 inhibition: beyond GLP-1. Vascul Pharmacol. 2011;55(1-3):10-6.

75. Ghorpade DS, Ozcan L, Zheng Z, Nicoloro SM, Shen Y, Chen E, Blüher M, Czech MP, Tabas I. Hepatocyte-secreted DPP4 in obesity promotes adipose inflammation and insulin resistance. Nature. 2018;555(7698):673-7.

76. Chang CY, Yeh YH, Chan YH, Liu JR, Chang SH, Lee HF, Wu LS, Yen KC, Kuo CT, See LC. Dipeptidyl peptidase-4 inhibitor decreases the risk of atrial fibrillation in patients with type 2 diabetes: a nationwide cohort study in Taiwan. Cardiovasc Diabetol. 2017;16(1):159.

77. Chang SH, Wu LS, Chiou MJ, Liu JR, Yu KH, Kuo CF, Wen MS, Chen WJ, Yeh YH, See LC. Association of metformin with lower atrial fibrillation risk among patients with type 2 diabetes mellitus: a population-based dynamic cohort and in vitro studies. Cardiovasc Diabetol. 2014;13:123.

78. Soeki T, Matsumoto K, Fukuda D, Uematsu E, Matsuura T, Tobiume T, Kusunose K, Ise T, Yamaguchi K, Yagi S, Yamada H. P2867 Vildagliptin reduces inducibility of atrial fibrillation in hypertensive rats complicated with diabetes mellitus. Eur Heart J. 2019;40(Supplement_1):ehz748-1176.

79. Yamamoto T, Shimano M, Inden Y, Takefuji M, Yanagisawa S, Yoshida N, Tsuji Y, Hirai M, Murohara T. Alogliptin, a dipeptidyl peptidase-4 inhibitor, regulates the atrial arrhythmogenic substrate in rabbits. Heart Rhythm. 2015;12(6):1362-9.

80. Proks P, Reimann F, Green N, Gribble F, Ashcroft F. Sulfonylurea stimulation of insulin secretion. Diabetes. 2002;51(suppl 3):S368-76.

81. Yu O, Azoulay L, Yin H, Filion KB, Suissa S. Sulfonylureas as initial treatment for type 2 diabetes and the risk of severe hypoglycemia. Am J Med. 2018;131:317.

82. Hanefeld M, Frier BM, Pistrosch F. Hypoglycemia and cardiovascular risk: is there a major link? Diabetes Care. 2016;39:S205-9.

83. Polovina M, Krljanac G, Ašanin M, Seferović PM. Crouching tiger, hidden dragon: insulin resistance and the risk of atrial fibrillation.

84. Park JK, Park JH, Lee YG, Shin JH, Lim YH, Heo R, Shin J. P5665 the independent effect of insulin resistance on the incidence of atrial fibrillation in non-diabetics. Eur Heart J. 2019;40(Supplement_1): ehz746-0608.

85. Deshmukh A, Ghannam M, Liang J, Saeed M, Cunnane R, Ghanbari H, Latchamsetty R, Crawford T, Batul SA, Chung E, Bogun F. Effect of metformin on outcomes of catheter ablation for atrial fibrillation. J Cardiovasc Electrophysiol. 2021;32(5):1232-9.

86. Pallisgaard JL, Brooks MM, Chaitman BR, Boothroyd DB, Perez M, Hlatky MA, Bypass Angioplasty Revascularization Investigation 2 Diabetes Study Group. Thiazolidinediones and risk of atrial fibrillation among patients with diabetes and coronary disease. Am J Med. 2018;131(7):805-12.

87. Okunrintemi V, Mishriky BM, Powell JR, Cummings DM. Sodium-glucose co-transporter-2 inhibitors and atrial fibrillation in the cardiovascular and renal outcome trials. Diabetes Obes Metab. 2021;23(1):276-80.

88. Li D, Liu Y, Hidru TH, Yang X, Wang Y, Chen C, Li KH, Tang Y, Wei Y, Tse G, Xia $Y$. Protective effects of sodium-glucose transporter 2 inhibitors on atrial fibrillation and atrial flutter: a systematic review and meta-analysis of randomized placebo-controlled trials. Front Endocrinol. 2021;12:196.

89. Bonora BM, Raschi E, Avogaro A, Fadini GP. SGLT-2 inhibitors and atrial fibrillation in the Food and Drug Administration adverse event reporting system. Cardiovasc Diabetol. 2021;20(1):1-8.

90. Fernandes GC, Fernandes A, Cardoso R, Penalver J, Knijnik L, Mitrani RD, Myerburg RJ, Goldberger JJ. Association of SGLT2 inhibitors with arrhythmias and sudden cardiac death in patients with type 2 diabetes or heart failure: a meta-analysis of 34 randomized controlled trials. Heart Rhythm. 2021.

\section{Publisher's Note}

Springer Nature remains neutral with regard to jurisdictional claims in published maps and institutional affiliations.
Ready to submit your research? Choose BMC and benefit from:

- fast, convenient online submission

- thorough peer review by experienced researchers in your field

- rapid publication on acceptance

- support for research data, including large and complex data types

- gold Open Access which fosters wider collaboration and increased citations

- maximum visibility for your research: over $100 \mathrm{M}$ website views per year

At BMC, research is always in progress.

Learn more biomedcentral.com/submissions 